ECCOMAS

Proceedia
COMPDYN 2021

$8^{\text {th }}$ ECCOMAS Thematic Conference on Computational Methods in Structural Dynamics and Earthquake Engineering M. Papadrakakis, M. Fragiadakis (eds.)

\title{
FRAGILITY ASSESSMENT OF THE ITALIAN MASONRY SCHOOL BUILDING ASSET FOR RISK EVALUATION AT NATIONAL SCALE
}

\author{
E. Saler ${ }^{1,2}$, V. Follador ${ }^{2}$, P. Carpanese ${ }^{2}$, and F. da Porto ${ }^{2}$ \\ ${ }^{1}$ Dept. of Civil, Environmental and Mechanical Engineering, University of Trento \\ Via Mesiano 77, 38123 Trento, Italy \\ e-mail: elisa.saler@unitn.it \\ ${ }^{2}$ Dept. of Geosciences, University of Padova \\ Via Gradenigo 6, 35131 Padova, Italy \\ \{veronica.follador,francesca.daporto\}@unipd.it; pietro.carpanese@phd.unipd.it
}

\begin{abstract}
Seismic risk and scenario assessments at large-scale provide important science-based tools to support governments and civil protection departments in investment policies and emergency planning. In this framework, school buildings are particularly significant due to the consequences of their damage or collapse and their relevance, as public buildings, in emergency planning. The evaluation of risk requires the definition of its components, i.e., hazard, exposure and vulnerability. To assess the seismic vulnerability of masonry school building assets, this paper presents the fragility curves derived for 265 building types, based on the Italian school building census. Parametric analyses were carried out on 14 representative prototype schools, using a mechanics-based model which considers both in-plane and out-of-plane mechanisms. More than 7500 sample fragilities were calculated and linearly combined to obtain fragility curves representing the Italian taxonomy of masonry school buildings. A macroseismic heuristic model from the literature was then calibrated to derive a fragility set for each school type, for five damage states, from slight damage to complete collapse. Finally, the paper compares the outcome fragility curves and fragility sets from the literature for residential buildings, highlighting the specificities of school seismic vulnerability. Indeed, masonry school buildings are frequently characterized by intrinsic geometric deficiencies due to significant inter-story height and great distance between transverse walls, both affecting the out-of-plane response and, therefore, the overall seismic fragility.
\end{abstract}

Keywords: Fragility curves, School buildings, Masonry buildings, Seismic risk, Large-scale assessment. 


\section{INTRODUCTION}

School buildings are crucial elements of structural and infrastructure assets for communities. The social impact of their collapse associated to seismic events is huge, in terms of both casualties and social dispersion. After the collapse of a primary school in San Giuliano di Puglia (Italy) in 2002 [1], the Italian government issued a national plan to evaluate the seismic vulnerability of the entire stock of relevant and strategic structures, including school buildings [2].

Detailed modeling and analyses are very time consuming, and therefore not suitable to manage large stocks of buildings, while tools based on fragility curves of building types better respond to this need. Fragility curves provide a correlation between a seismic intensity measure, such as the Peak Ground Acceleration (PGA), and the probability that a structure exceeds a damage state (DS). Fragility curves for school buildings were obtained for Nepalese schools, after processing data on observed damage caused by the 2015 Nepal earthquake [3], while Gentile et al. [4] derived fragility curves for Indonesian schools by means of non-linear dynamic analyses.

Different approaches are available to define fragility curves: empirical, based on observed damage after a seismic event [5-8]; mechanical, based on structural modeling, either detailed [9] or simplified [10-13]; and hybrid, based on both empirical data and models [14, 15]. These methods have been largely applied to ordinary and residential buildings. Moreover, vulnerability assessment at urban scale of the built asset specific for a regional area [16] has aroused a large interest, as it allows a more precise estimation of risk.

The taxonomy of buildings exposed to risk is fundamental to define building types and their distribution at large scale, requiring typological analyses of the building census of the analyzed area. In particular for Italy, regional taxonomies have been provided in the literature, while the evaluation of national macro-classes representative of the entire national school asset has yet to be defined. A typological study of masonry school buildings in the crater of the Central Italy seismic sequence (2016) was provided by Ottonelli et al. [17], while masonry school types were classified for the Friuli-Venezia Giulia region by Gattesco and Boem [18].

Especially for the Italian framework, the fragility analysis of specific classes of structures, such as school buildings, based on an extensive taxonomy describing the national stock, is required to assess risk at large scale and to optimize the allocation of funds for mitigation strategies. This aim is carried out by a cooperative national project (ReLUIS-DPC Project 2019-2021) by will of the Italian Department of Civil Protection, in which this contribution is included.

This paper presents the derivation of seismic fragility curves for unreinforced masonry (URM) school buildings by means of extensive parametric analyses carried out by applying a mechanics-based model $[19,20]$ which considers both the in-plane (IP) and the out-of-plane (OOP) mechanisms, as well as an index of the structural quality [21]. The approach has been already effectively applied to residential URM buildings and validated by simulating the damage scenario caused by the 2009 L'Aquila earthquake $[22,23]$. In the present paper, a set of 14 representative prototype school buildings were analyzed, varying different parameters, i.e., number of stories, quality of construction details, floor weight, type of masonry and related panel thickness. The contribution aims to provide fragility curves which cover all the macro-classes based on the Italian school census, defined by a limited number of parameters, i.e., construction age, number of stories, plan area, and type of masonry. 


\section{ITALIAN SCHOOL BUILDING ASSET}

A general taxonomy of Italian school buildings was derived according to the School Building Registry (SBR) of the Italian Ministry of Education [24], which classifies a large amount of the Italian school asset, based on a limited number of parameters, i.e., construction material and age, number of stories, plan area, and types of floors and roof. In this framework, data from the Italian SBR (2005) for masonry schools, amounting to more than ten thousand buildings, were used to define the macro-classes for which the fragility model, presented hereinafter, was derived.

Figure 1 illustrates the distribution of typological characteristics of masonry school buildings comprised in the national census. In particular, Figure 1a shows the distribution of construction ages, which appears to be covered quite evenly. Then Figure $1 \mathrm{~b}$ provides the distribution of the number of stories, with a peak corresponding to the case of two-story buildings, and Figure 1c shows the prevalence of small to medium schools, according to their plan area. Lastly, the combinations of couples of these parameters are shown in Figure 1d with the number of stories given the construction age, Figure 1e with the distribution of plan area given the construction age, and Figure $1 \mathrm{f}$ with the number of stories associated to the plan area.
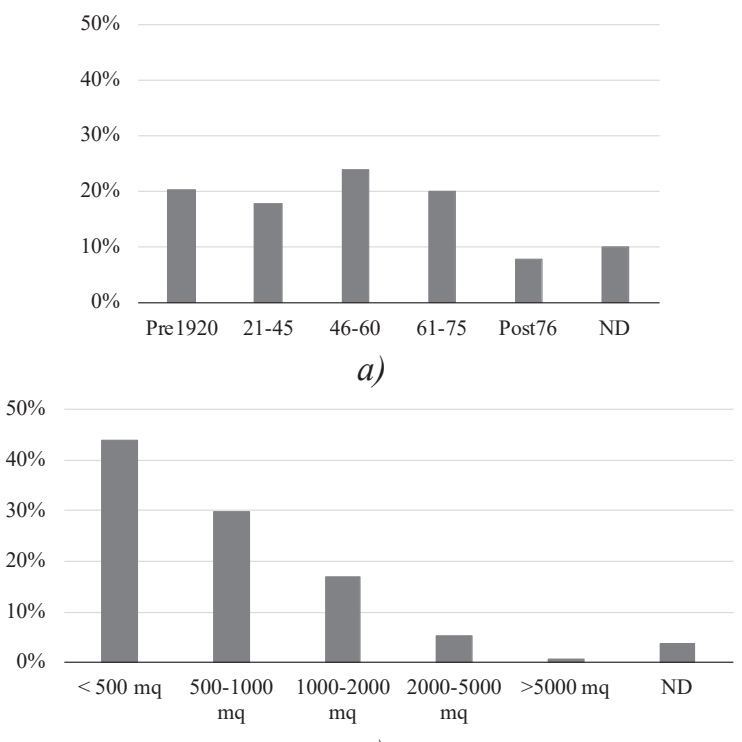

c)

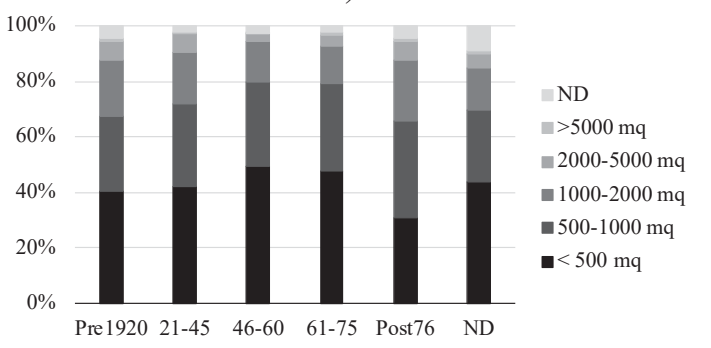

e)

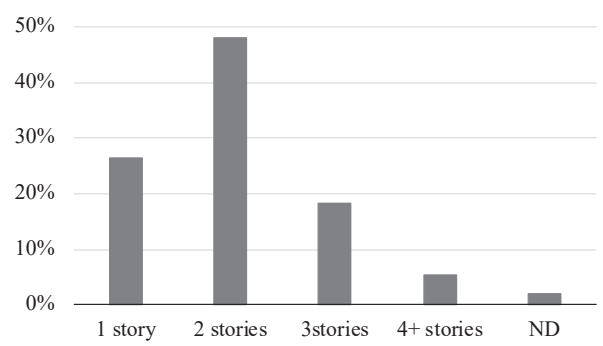

b)

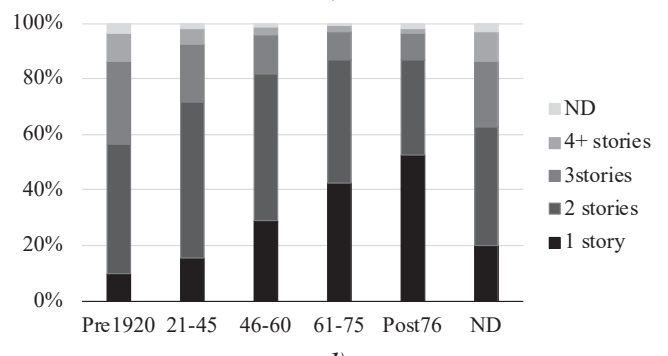

d)

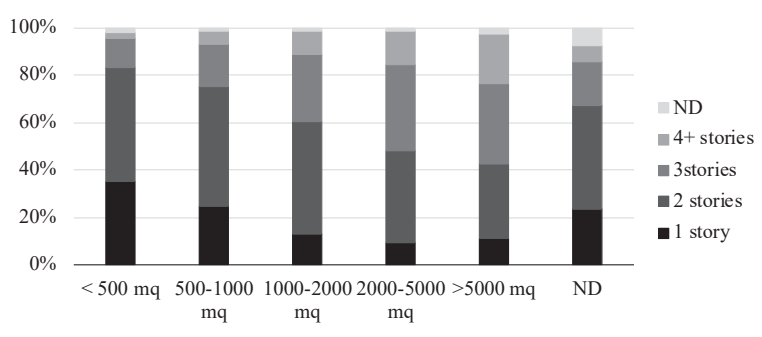

f)

Figure 1: Distribution of typological characteristics of masonry buildings in Italian School Building Registry.

The analysis of the distribution of the typological characteristics of the masonry school buildings in the SBR allowed the definition of a finite number of prototype buildings to be used in the derivation of fragility curves, as described in the following sections. Considering significant combinations of the typological parameters, 14 masonry school buildings were selected from the databases collected by research groups from the Universities of Genova, Pa- 
dova, and Trieste, so as to ensure a good representativeness of the national school building taxonomy; their typological characteristics are reported in Table 1. The typical shapes of school building plans, included in the analysis by choosing representative prototype buildings, are shown in Figure 2.

\begin{tabular}{ccccc}
\hline School ID & Age & N. stories & Plan area $\left[\mathbf{m}^{2}\right]$ & Plan shape \\
\hline S1 & Before 1920 & 3 & $<500$ & Rectangular \\
S2 & Before 1920 & 2 & $>2000$ & U-shape \\
S3 & Before 1920 & 2 & $1000-2000$ & Cloister \\
S4 & Before 1920 & 3 & $1000-2000$ & U-shape \\
S5 & $1921-1945$ & 2 & $500-1000$ & Rectangular \\
S6 & $1921-1945$ & 2 & $<500$ & Rectangular \\
S7 & $1921-1945$ & 2 & $<500$ & T-shape \\
S8 & $1921-1945$ & 2 & $1000-2000$ & U-shape \\
S9 & $1921-1945$ & 2 & $500-1000$ & T-shape \\
S10 & $1946-1960$ & 2 & $1000-2000$ & L-shape \\
S11 & $1946-1960$ & 2 & $<500$ & Rectangular \\
S12 & $1946-1960$ & 2 & $<500$ & Rectangular \\
S13 & $1961-1975$ & 1 & $<500$ & Square \\
S14 & After 1976 & 1 & $<500$ & Square \\
\hline
\end{tabular}

Table 1: Typological characteristics of prototype school buildings.

Small to medium
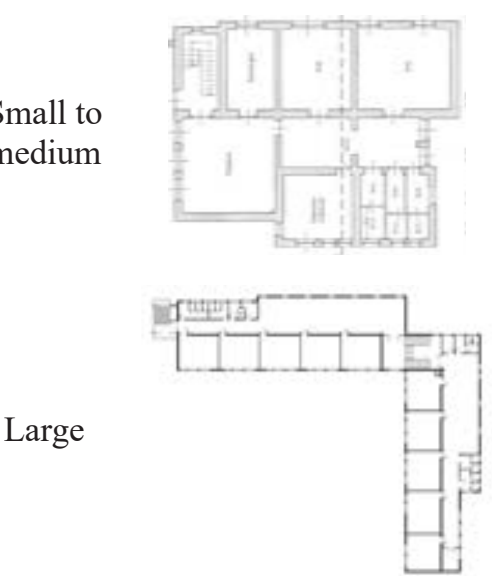
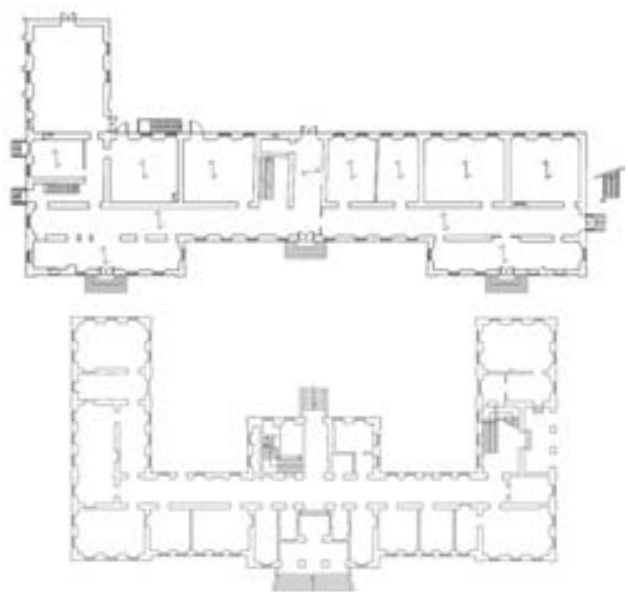

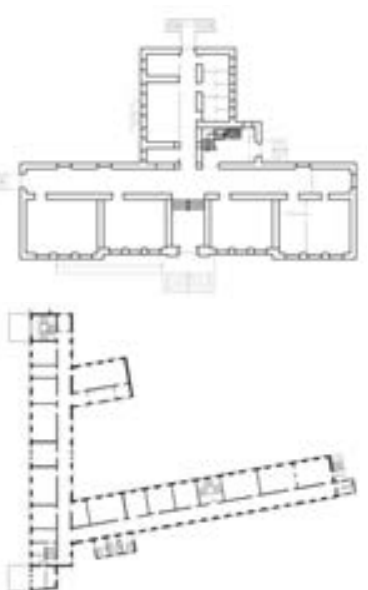

Figure 2: Typical shapes of school building plans.

\begin{tabular}{ccccc}
\hline $\begin{array}{c}\text { N. } \\
\text { stories }\end{array}$ & Construction details & Floor weight & Type of masonry & $\begin{array}{c}\text { Thickness of } \\
\text { masonry [cm] }\end{array}$ \\
\hline 1 & $\begin{array}{c}\text { No ring-beam, no tie-rod } \\
\text { (LQD) }\end{array}$ & Light & Random rubble & $30-70$ \\
\hline 2 & $\begin{array}{c}\text { Tie-rods } \\
\text { (MQD) }\end{array}$ & Heavy & Stone ashlar & $30-70$ \\
\hline 3 & $\begin{array}{c}\text { Ineffective ring-beam } \\
\text { (HQD ineff) }\end{array}$ & Clay bricks w/ lime mortar & $25-50$ \\
\hline 4 & $\begin{array}{c}\text { Effective ring-beam } \\
\text { (HQD) }\end{array}$ & Clay blocks w/ cement mortar & $30-45$ \\
\hline
\end{tabular}

Table 2: Parameters and ranges of variation considered in parametric analyses.

Preserving the geometric properties of each building, a parametric analysis was carried out, increasing the size of the school dataset, which lead to more than 7500 realizations imple- 
mented through the simplified mechanical model. Table 2 reports parameters and their range of variation included in the analyses.

The mechanical properties of masonry were assumed according to Italian Code [25], considering two values for the masonry strength: the minimum value reported in the regulation, and a maximum value obtained by applying code-compliant improving coefficients, to take into account possible interventions carried out during the lifetime of the structure.

\section{MECHANICS-BASED APPROACH FOR FRAGILITY ASSESSMENT}

The simplified mechanics-based approach Vulnus $4.0[19,20]$, which allows the implementation of a significant amount of analyses with a limited computational effort, was applied for the fragility assessment of the above described prototype schools. The modeling procedure allows seismic analyses to be implemented accounting for both the In-Plane (IP) shear resistance of the building and the trigger of potential Out-Of-Plane (OOP) mechanisms, together with a vulnerability rate deriving from the II level GNDT form [21]. Vulnus 4.0 provides three outcome indexes: i) the first index $\left(i_{1}\right)$ expresses the ratio, for the weakest plan direction, between the IP shear resistance and the weight of the building; ii) the second index $\left(i_{2}\right)$ describes the susceptibility to OOP mechanisms (i.e., overturning, flexural failure, and arch compression failure), calculated by means of kinematic analyses; and iii) the third index $\left(i_{3}\right)$ considers qualitative factors, included in II level GNDT form, which can affect the seismic vulnerability of a building, such as the masonry quality as well as the type of floors, also considering those configurations which strongly worsen the seismic response (i.e., heavy and rigid floor on weak random masonry).

Then, the combination of the indexes is carried out through fuzzy set theory, allowing the probabilistic evaluation of the influence of both not quantifiable parameters, summarized in the $i_{3}$ index, and uncertainties of quantifiable parameters (e.g., mechanical properties of masonry), which are considered in the calculation of indexes $i_{1}$ and $i_{2}$. The outcome of vulnerability analysis with Vulnus 4.0 consists in three fragility curves: an average curve, called white, which describes the most probable distribution; and two extreme conditions, defined as lower and upper, representing the lower and the upper bounds, respectively.

Fragility curves, which expresses the probability of exceedance of a damage state, are derived as log-normal cumulative probability functions, which are described by two parameters: the mean value (IMmean) and the standard deviation $(\beta)$.

The resulting set represents the cumulative probability of exceeding a medium-severe damage state (DS), according to the definition provided by the European macro-seismic scale (EMS98) [26], which is an intermediate DS between 2 (i.e., trigger of OOP mechanisms) and 3 (i.e., IP global shear failure). The DS identified by the Vulnus 4.0 fragility set is therefore conventionally referred to as DS2-3, hereinafter.

As mentioned before, the parametric analysis generated more than 7500 realizations and thus, the same amount of DS2-3 fragility sets, which were then combined to finally derive 265 fragility sets, to be associated with school macro-classes, according to the typological parameters included in the Italian school building census. An exposure matrix was assumed, based on expert judgement, to linearly combine curves obtained from each case of the parametric analysis, keeping the white, lower and upper curves separate. Table 3 reports the percentage of the exposure matrix used for the recombination in macro-classes starting from subtypes of masonry, while Table 4 shows the percentage of recombination for different level of quality details, whose definition has been given in Table 2 .

The fragility sets for macro-classes describing the damage state 2-3 were then extended to a complete set of five fragility curves, capable of describing the probability of exceedance of 
the five damage states given by the EMS98 [26], from DS1 (slight damage) to DS5 (complete collapse).

The final complete sets took into account both the average white curve and the extreme bounds, by means of a geometric combination, detailed as follows. The above described procedure was developed for residential buildings [27] and afterwards, in the present work, applied to school buildings.

\begin{tabular}{cccccc}
\hline & Before 1920 & $1921-45$ & $1946-60$ & $1961-75$ & After 1976 \\
\hline Random rubble & $30 \%$ & $30 \%$ & $10 \%$ & $10 \%$ & - \\
\hline Stone ashlar & $35 \%$ & $35 \%$ & $27 \%$ & $27 \%$ & $10 \%$ \\
\hline Clay bricks & $35 \%$ & $35 \%$ & $54 \%$ & $44 \%$ & $27 \%$ \\
\hline Clay blocks & - & - & $9 \%$ & $19 \%$ & $63 \%$ \\
\hline
\end{tabular}

Table 3: Assumed exposure matrix of type of masonry during construction ages.

\begin{tabular}{cccccc}
\hline & Before 1920 & $1921-45$ & $1946-60$ & $1961-75$ & After 1976 \\
\hline LQD & $20 \%$ & $15 \%$ & $10 \%$ & - & - \\
\hline MQD & $50 \%$ & $35 \%$ & $50 \%$ & $30 \%$ & $15 \%$ \\
\hline HQD_ineff & $30 \%$ & $30 \%$ & - & - & - \\
\hline HQD & - & $20 \%$ & $40 \%$ & $70 \%$ & $85 \%$ \\
\hline
\end{tabular}

Table 4: Assumed exposure matrix of quality of construction details during construction ages.

To obtain fragility sets representing five DSs, each DS2-3 fragility set was referred to the fragility model proposed by Lagomarsino and Cattari, in 2014 [13], which was derived from a previously presented macro-seismic model [15]. For the present application, the correlation law between the Peak Ground Acceleration (PGA) and the macro-seismic intensity was set according to Margottini et al. [28]. The reference model represents fragility distributed on five DSs for the six vulnerability classes (from A to F) defined by EMS98 [26], on the basis of the intrinsic correlation between macro-seismic intensity and damage state. The macro-seismic reference model was thus calibrated on the macro-class fragility sets obtained with the mechanical procedure Vulnus 4.0, through the steps described as follows:

1. An average curve DS2-3 was derived for the six vulnerability classes, through the linear combination of the available DS2 and DS3 fragility curves. Figure 3a shows fragility curves from macro-seismic model for all vulnerability classes, with DS2 and DS3 curves highlighted in solid blue lines, and DS2-3 highlighted in solid black lines.

2. Each fragility set from the mechanical model was then represented through a combination of compatible DS2-3 curves of two vulnerability classes, calculated at the previous step. A genetic algorithm (NSGA-II [29]) was implemented to evaluate the optimal linear combination, by minimizing both the absolute and the relative errors between the curves, calculated through the least squares and the difference between the areas, respectively.

3. A set of five fragility curves (i.e., representing five DSs) was derived for each macroclass of school buildings through the optimal coefficient that was previously calculated, for the linear combination of vulnerability classes. Figure $3 \mathrm{~b}$ reports, as an example, the fragility curve DS2-3 from the mechanical model for two-story masonry schools built before 1920 (solid red line), which resulted to be an optimal combination of DS2-3 curves for vulnerability classes B and $\mathrm{C}$, which are represented in blue and black solid lines, respectively. Fragility curves for DSs from 1 to 5, for the school macro-class, was then derived as a combination of each DS curves from the macro-seismic model, in this case considering the curves associated with vulnerability classes B and C. 
This procedure was applied to each macro-class of school buildings for all the curves previously derived through Vulnus 4.0, namely the white, lower and upper curves.

Finally, a procedure for geometric combination (named LUW $[22,23]$ ) was implemented in order to include, in the proposed fragility model, the uncertainties considered in Vulnus 4.0 analysis by means of fuzzy theory. Thus, the procedure allowed white, upper and lower curves to be combined for each macro-typology and for each DS.

The LUW procedure preserves the mean value of the white curve; it uses upper and lower distributions in $2.5 \%$ and $97.5 \%$ fractals of the white probability, respectively. Between $2.5 \%$ and $50 \%$ of the white probability, it linearly combines white and upper curves, while a linear combination of white and lower curves is calculated between $50 \%$ and $97.5 \%$.

For example, Figure 4 illustrates how LUW procedure was applied to two-story masonry schools built before 1920 and, thereby, the final fragility set was derived.

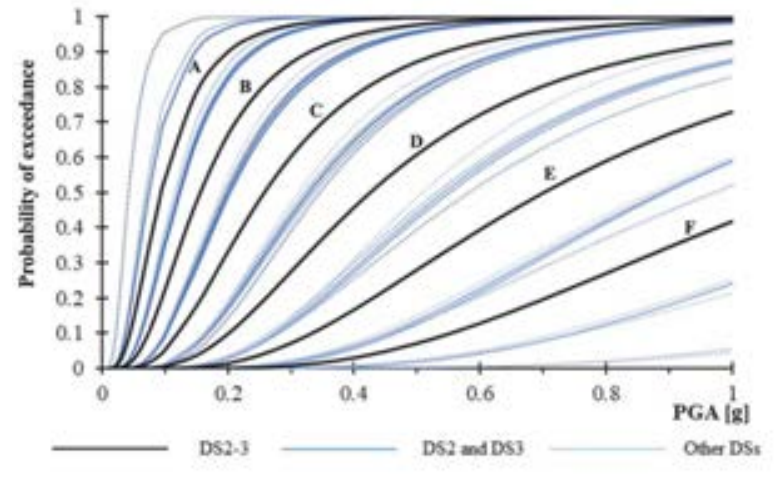

a)

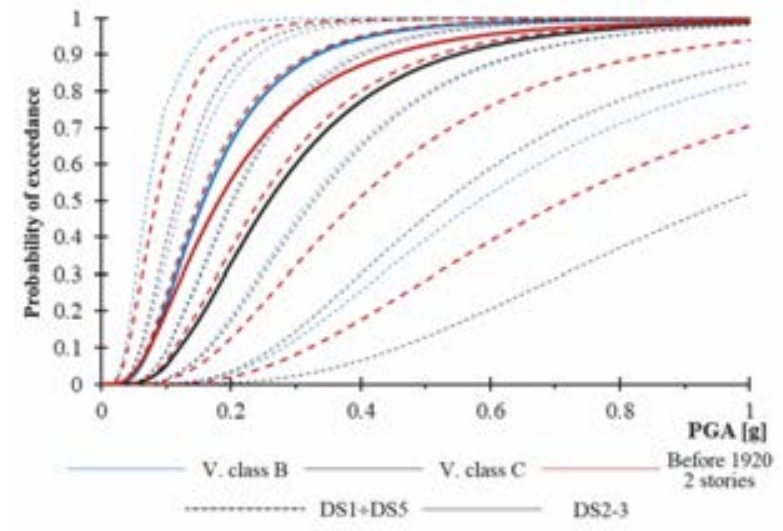

b)

Figure 3: a) Average curves DS2-3 for macro-seismic reference model, b) calibration of macro-seismic model for one school macro-class.

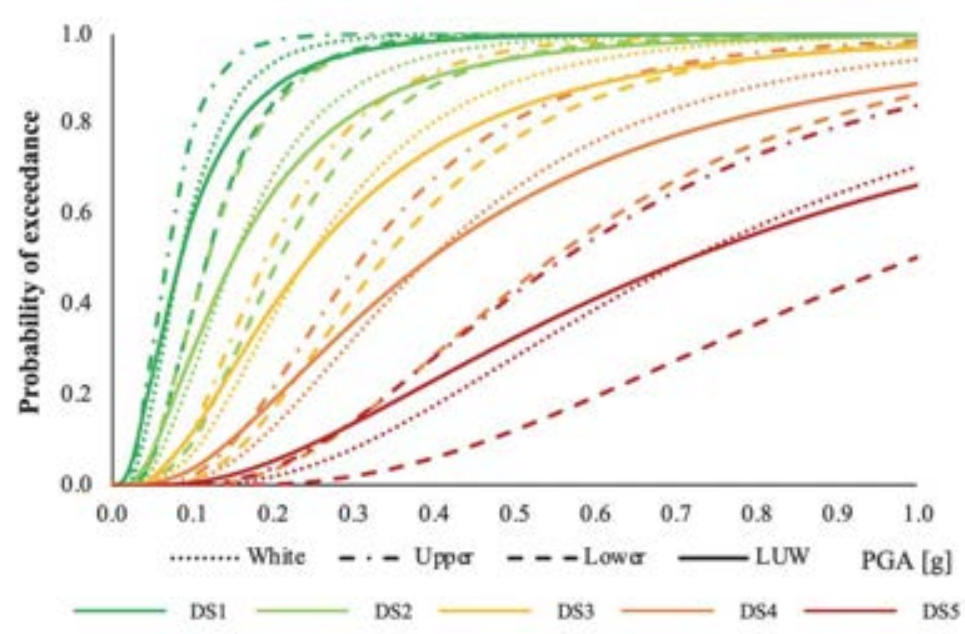

Figure 4: Application of LUW procedure on a set of fragility curves.

\section{RESULTS AND PROPOSED FRAGILITY MODEL}

This section presents the outcomes of this study, starting from the fragility sets associated to a Damage State 2-3, which were obtained through the mechanical approach Vulnus 4.0. Figure 5 illustrates the mechanical fragility curves obtained from the combination, according to the above-described exposure matrix, of the fragility curves resulting from the above- 
described extensive parametric analysis. The figure reports a summary of the results considering two parameters (i.e., number of stories and construction age).
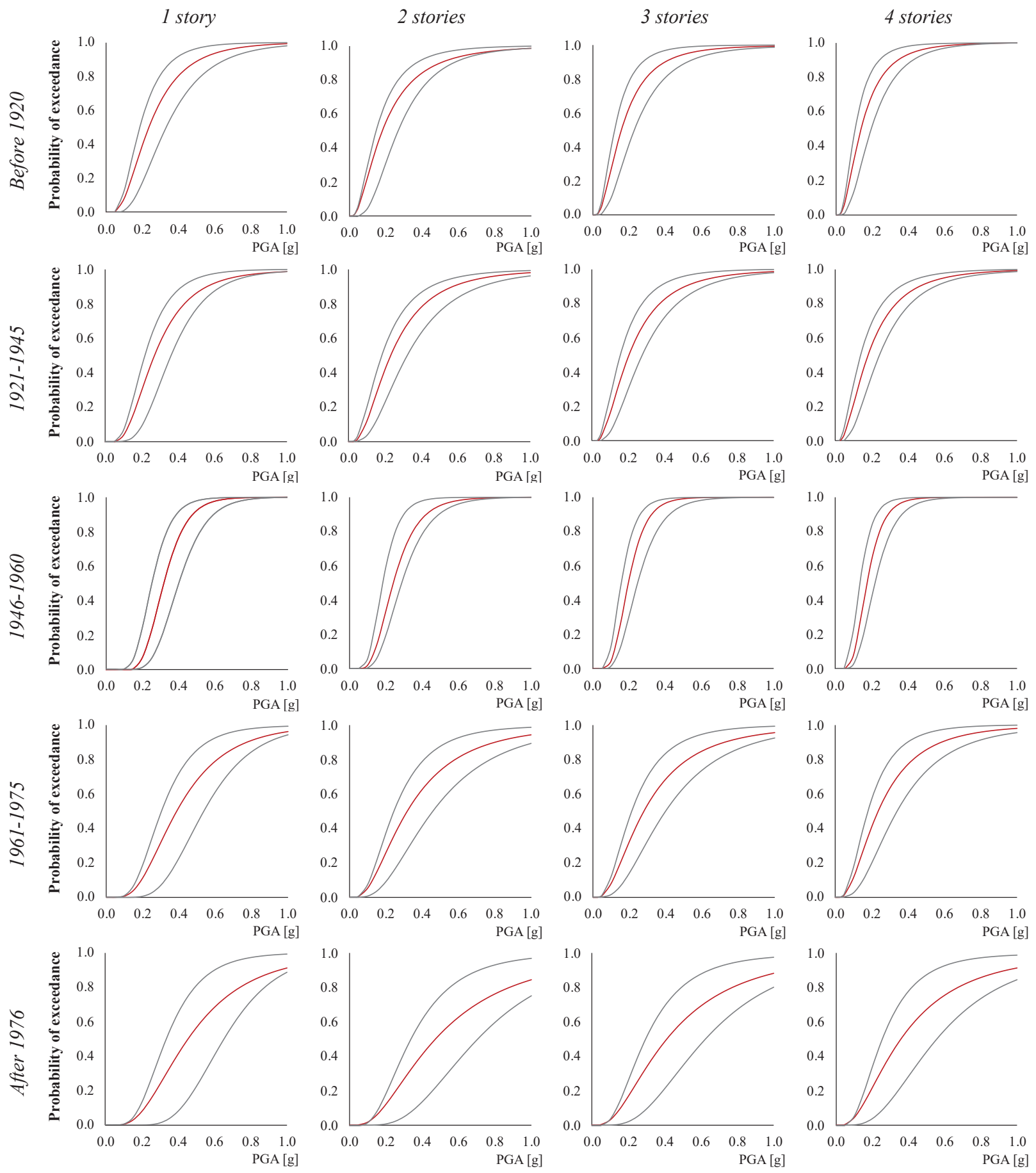

Figure 5: Mechanical fragility curves for DS2-3; white curves in red between upper and lower bounds.

Macro-class fragility tends to slightly increase as the number of stories increases, while it appears to be more evidently influenced by the construction age. Furthermore, an increase in the dispersion was observed as the overall fragility decreases (e.g., for more recent construction ages).

A novel fragility model was derived for Italian masonry school buildings for macro-classes based on a limited number of parameters included in the SBR (i.e., number of stories, con- 
struction age, plan area, and type of masonry). In addition, more general classes were derived from the aggregation of specific school types, for instance all single-story masonry schools built before 1919 (in this case, curves for specific plan area and type of masonry were combined together).
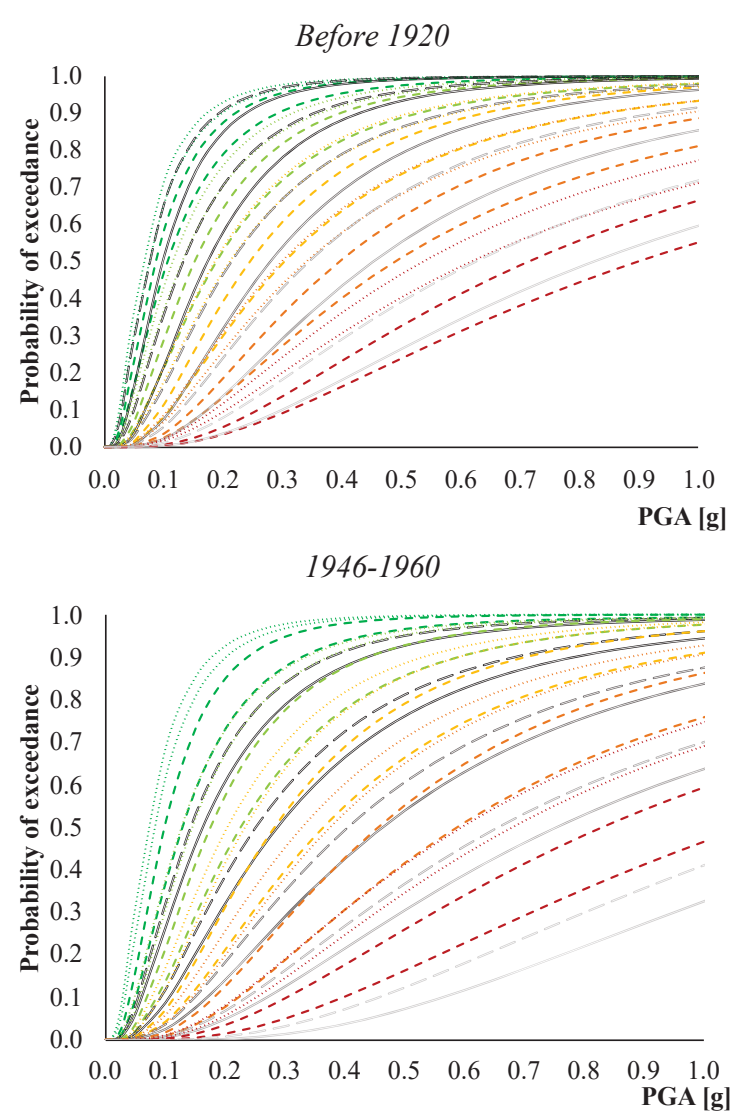

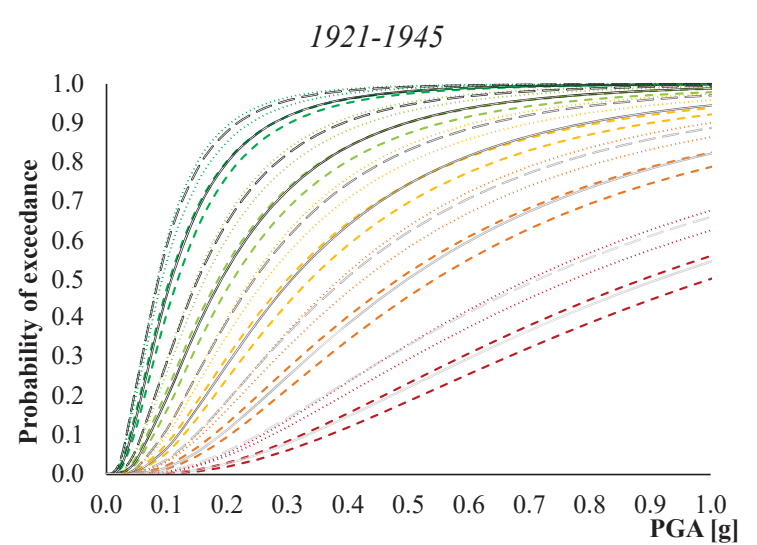

$1961-1975$

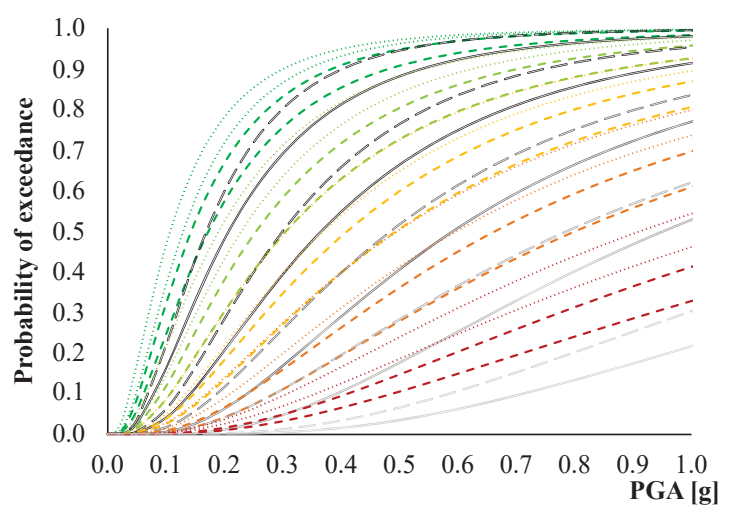

After 1976

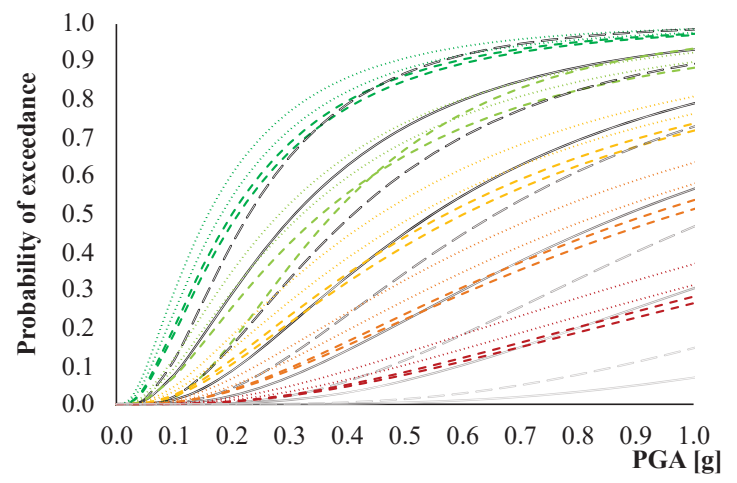

- - - School buildings $1-2$ stories

School buildings 3-4 stories

- Residential baildings $1-2$ stories [2.2]

- - Residential buildings 3-4 stories [22]

Figure 6: Comparison between fragility models for masonry schools and for masonry residential buildings [22].

The reduction in the number of parameters allowed the proposed fragility model to be compared to fragility curves from the literature, previously derived for residential buildings by Donà et al. [22]. Since the development methodology was the same, the differences in the fragility models are due to the variation of building types. Figure 6 reports the proposed fragility model for the Italian masonry school buildings classified, according to the number of stories and the construction age, and their comparison to fragility curves for residential buildings of comparable macro-classes. 
It can be observed that, before 1945, the fragilities of schools and residential buildings are similar. On one hand, in fact, better material quality and more frequent applications of retrofit and restoration interventions can be expected for public relevant buildings such as schools; on the other hand, school buildings present an intrinsic geometric vulnerability (i.e., higher interstory and great distance between transverse walls, orthogonal to façades) which increase their susceptibility towards OOP mechanisms. After 1945, also the residential construction industry improved, as described in the reference study by Donà et al. [22]. Thus, the geometric vulnerability factors of schools prevailed in the fragility model and, therefore, school structures appear to be more fragile than residential buildings. A note of caution is due regarding the interpretation of results as they are strongly influenced by the assumed exposure matrix for the combination of school macro-classes.

The trends of the mean value of the proposed fragility curves are reported in Figure 7 to highlight how they can be affected by the different parameters taken into account. The factors increasing vulnerability were confirmed to be the age, the great number of stories, the plan area, which is often related to plan complexity, and the poor quality of the material.

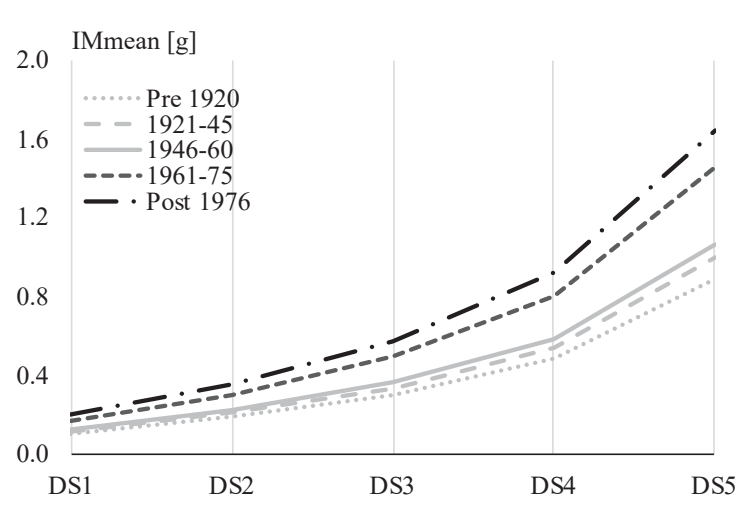

a)

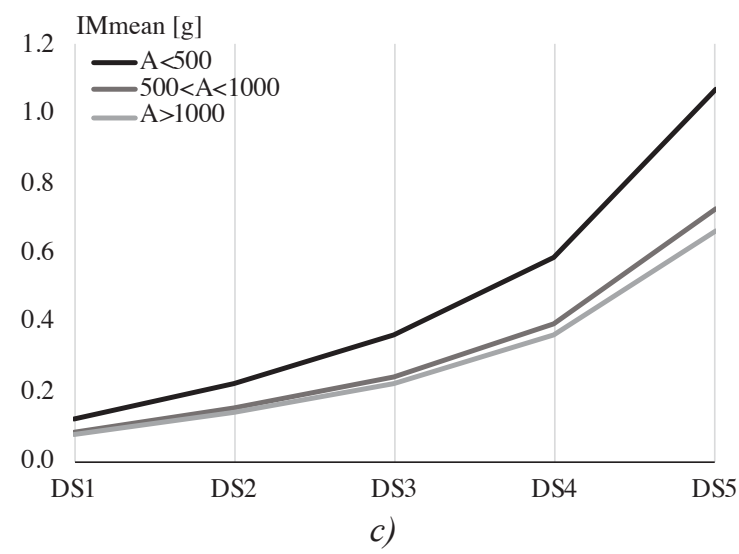

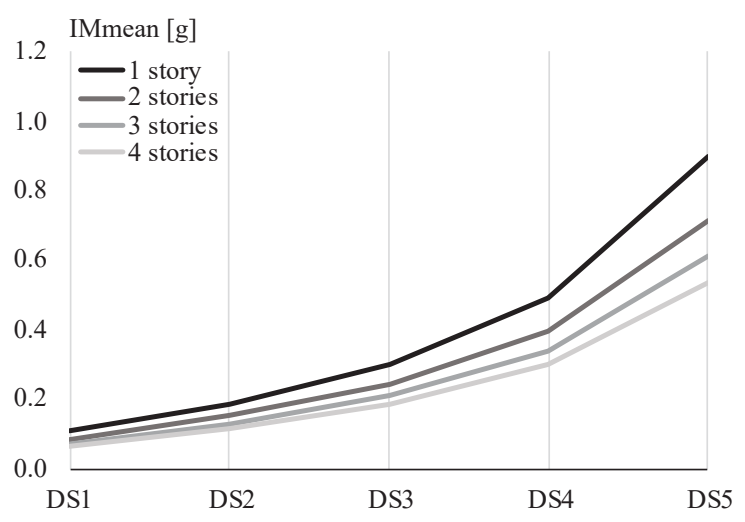

b)

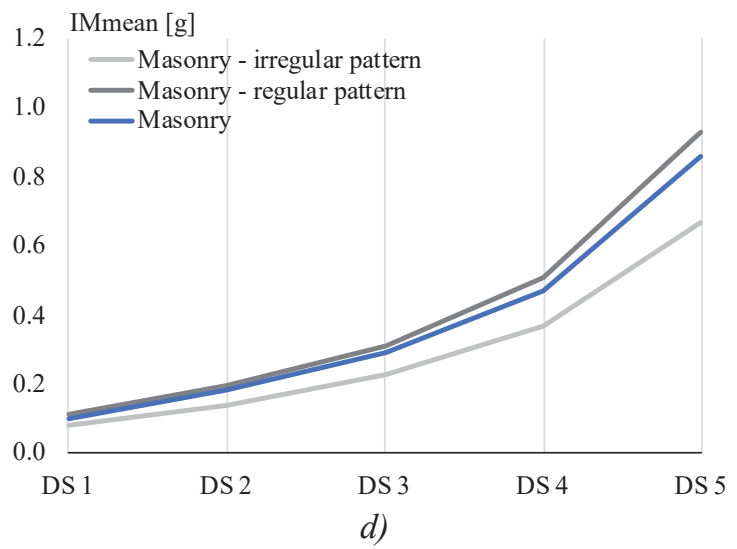

Figure 7: Trend of mean value as following parameters vary: a) construction age, b) number of stories, c) plan area in square meters, and d) type of masonry.

Focusing on construction age, two groups can be identified due to a perceptible gap in the trends of mean values: before 1960 and after 1960, when modern clay blocks and high-quality construction details began to spread in the construction use, years before code provisions (which started, in Italy, in the 1980s) [30]. Plan area appeared to affect the vulnerability and two groups can be identified based on their response: small buildings and, on the other hand, medium-large structures. Thus, for plan area greater than $500 \mathrm{~m}^{2}$, an increased vulnerability due to plan complexity shall be expected. 


\section{CONCLUSIONS}

- The present paper has illustrated the derivation on fragility curves for the Italian masonry school building asset, on the basis of a limited number of parameters included in the Italian school building registry: the construction age, the number of stories, the plan area, and the type of masonry.

- The simplified mechanical modeling procedure Vulnus 4.0 was used, as it allows a large amount of analyses to be performed in a suitably short time. The mechanical model considers both IP and OOP mechanisms, together with an index which summarizes qualitative vulnerability factors, according to the II level GNDT form [21].

- A parametric analysis was implemented through Vulnus 4.0, resulting in a fragility set, comprised of three fragility curves (i.e., average white curve, a lower-bound and an upper-bound), for each macro-class of school structures. Fragility sets were associated to an intermediate DS between 2 and 3, and therefore called DS2-3. Then, a macro-seismic model from the literature $[13,15]$ was calibrated to extend the mechanical fragility sets to five damage states, according to EMS98 [26]. Lastly, average white curves were combined to upper and lower bounds increasing dispersion, thereby leading to a better treatment of uncertainties.

- A novel fragility model was proposed and compared to a likewise developed fragility model from the literature for masonry residential buildings [22]. Interestingly, for the construction period before 1919 and between the two World Wars, school buildings and residential structures present similar fragilities, suggesting that the intrinsic geometric vulnerability of schools was balanced by the better quality of public construction industry. Otherwise, after 1945, also the residential construction industry had improved and, therefore, school buildings appear to be more seismically fragile than ordinary buildings.

- This research contributes to current knowledge of seismic risk assessment and mitigation by providing a broad fragility assessment of a particular type of relevant structures (i.e., school buildings), at national scale. This study was focused on the Italian building asset and construction use, to which both the database analysis and the exposure matrix are referred. A limitation of this study was the lack of information regarding the distribution of masonry quality and construction details during the ages at national scale; this additional information would have allowed the exposure matrices, here based on expert judgement, to be calibrated. Further investigations are requested to retrieve data, consistent at national scale, for specific types of structures.

- This contribution will be used to develop maps of seismic risk and damage scenario for Italy. The proposed fragility sets will represent the vulnerability component in the convolution with hazard and exposure to evaluate seismic risk. This evaluation will be possible thanks to the IRMA platform [31], specifically developed by Eucentre, within the framework of a cooperative national project. The final aim will be a deep knowledge of seismic risk, to mitigate the impact of earthquakes which have caused casualties, huge economic losses on the residential asset [32,33] and on the production sector [34, 35] and, above all for schools, an unquantifiable social impact. 


\section{ACKNOWLEDGEMENTS}

Special thanks are due to the Italian Department of Civil Protection (DPC), which funded this study in the framework of the ReLUIS-DPC Project 2019-2021 - Work Package 4: MARS (MAps of Risk and Scenarios of seismic damage) - Task 7: Fragility models and curves for schools and other strategic or relevant buildings. A special thanks to the Work Group for the effective cooperation, especially to the research units of the Universities of Genova, coordinated by Prof. Serena Cattari, and Trieste, coordinated by Prof. Natalino Gattesco, for sharing data of prototype schools included in the study.

\section{REFERENCES}

[1] N. Augenti, E. Cosenza, M. Dolce, G. Manfredi, A. Masi, L. Samela, Performance of school buildings during the 2002 Molise, Italy, earthquake, Earthq. Spectra. 20, 2004. https://doi.org/10.1193/1.1769374.

[2] OPCM 3431/2005, All 2 - Norme Tecniche per il Progetto, la Valutazione e L'Adeguamento Sismico degli Edifici (in Italian), Ordinary Suppl. Off. Gazzette Ital. Repub. N¹07 10th May 2005. 1-139.

[3] N. Giordano, F. De Luca, A. Sextos, F. Ramirez Cortes, C. Fonseca Ferreira, J. Wu, Empirical seismic fragility models for Nepalese school buildings, Nat. Hazards 105, 339-362 (2020). https://doi.org/10.1007/s11069-020-04312-1.

[4] R. Gentile, C. Galasso, Y. Idris, I. Rusydy, E. Meilianda, From rapid visual survey to multi-hazard risk prioritisation and numerical fragility of school buildings, Nat. Hazards Earth Syst. Sci. 19, 2019, 1365-1386. https://doi.org/10.5194/nhess-19-1365-2019.

[5] M. Rota, A. Penna, C.L. Strobbia, Processing Italian damage data to derive typological fragility curves, Soil Dyn. Earthq. Eng. 28, 2008 933-947. https://doi.org/10.1016/j.soildyn.2007.10.010.

[6] A. Rosti, M. Rota, A. Penna, Empirical fragility curves for Italian URM buildings, Bull. Earthq. Eng., 2020. https://doi.org/10.1007/s10518-020-00845-9.

[7] G. Zuccaro, F.L. Perelli, D. De Gregorio, F. Cacace, Empirical vulnerability curves for Italian masonry buildings: evolution of vulnerability model from the DPM to curves as a function of acceleration, Bull. Earthq. Eng., 2020. https://doi.org/10.1007/s10518020-00954-5.

[8] C. Del Gaudio, G. De Martino, M. Di Ludovico, G. Manfredi, A. Prota, P. Ricci, G.M. Verderame, Empirical fragility curves for masonry buildings after the 2009 L'Aquila, Italy, earthquake, Bull. Earthq. Eng. 17, 2019, 6301-6330. https://doi.org/10.1007/s10518-019-00683-4.

[9] A. Masi, A. Digrisolo, V. Manfredi, Fragility curves of gravity-load designed RC buildings with regularity in plan, Earthq. Struct. 9, 2015, 1-27. https://doi.org/10.12989/eas.2015.9.1.001.

[10] B. Borzi, H. Crowley, R. Pinho, Simplified pushover-based earthquake loss assessment (SP-BELA) method for masonry buildings, Int. J. Archit. Herit. 2, 2008, 353-376. https://doi.org/10.1080/15583050701828178.

[11] A.B. Acevedo, J.D. Jaramillo, C. Yepes, V. Silva, F.A. Osorio, M. Villar, Evaluation of 
the seismic risk of the unreinforced masonry building stock in Antioquia, Colombia, Nat. Hazards. 86, 2017, 31-54. https://doi.org/10.1007/s11069-016-2647-8.

[12] D. D’Ayala, A. Meslem, D. Vamvatsikos, K. Porter, T. Rossetto, V. Silva, Guidelines for Analytical Vulnerability Assessment of Low/Mid-Rise Buildings, Vulnerability Global Component Project., GEM Tech. Rep. 2015-08 v1.0.0. 08, 2015, 162.

[13] S. Lagomarsino, S. Cattari, Fragility Function of Masonry Buildings, in: K. Pitilakis, H. Crowley, A.M. Kaynia (Eds.), SYNER-G Typology Defin. Fragility Funct. Phys. Elem. Seism. Risk Build. Lifelines, Transp. Networks Crit. Facil., 2014. https://doi.org/10.1007/978-94-007-7872-6.

[14] A.J. Kappos, G. Panagopoulos, C. Panagiotopoulos, G. Penelis, A hybrid method for the vulnerability assessment of R/C and URM buildings, Bull. Earthq. Eng. 4, 2006, 391-413. https://doi.org/10.1007/s10518-006-9023-0.

[15] S. Lagomarsino, S. Giovinazzi, Macroseismic and mechanical models for the vulnerability and damage assessment of current buildings, Bull. Earthq. Eng. 4, 2006, 415-443. https://doi.org/10.1007/s10518-006-9024-Z.

[16] M. Vettore, M. Donà, P. Carpanese, V. Follador, F. da Porto, M.R. Valluzzi, A Multilevel Procedure at Urban Scale to Assess the Vulnerability and the Exposure of Residential Masonry Buildings: The Case Study of Pordenone, Northeast Italy, Heritage 3, 2020 1433-1468. https://doi.org/10.3390/heritage3040080.

[17] D. Ottonelli, S. Alfano, S. Cattari, M. Di Ludovico, A. Prota, Structural and damage data analysis of a stock of URM schools struck by the 2016/2017 Central Italy earthquake, in: XVIII CONVEGNO ANIDIS - L'ingegneria Sismica Ital., Pisa University Press, Ascoli Piceno, 15-19 September 2019, 2019: pp. 43-53.

[18] N. Gattesco, I. Boem, Classification of Friuli-Venezia Giulia masonry school buildings for seismic risk models purposes, in: XVIII CONVEGNO ANIDIS - L'ingegneria Sismica Ital., Ascoli Piceno, 15-19 September 2019, 2019: pp. 79-86.

[19] A. Bernardini, R. Gori, C. Modena, M.R. Valluzzi, Vulnus 4.0 - Automatic procedure for the seismic vulnerability analysis of masonry buildings (in Italian), 2009.

[20] M.R. Valluzzi, User Manual of Vulnus_4.0, original program by Bernardini Gori A, Modena $\mathrm{R} \mathrm{C}, \mathrm{Vb}$ version edited by Valluzzi MR, with contributions by Benincà $\mathrm{G}$, Barbetta E, Munari M (in Italian), 2009.

[21] GNDT-SSN, Scheda di esposizione e vulnerabilità e di rilevamento danni di primo livello e secondo livello (muratura e cemento armato) (in Italian), 1994.

[22] M. Donà, P. Carpanese, V. Follador, L. Sbrogiò, F. da Porto, Mechanics-based fragility curves for Italian residential URM buildings, Bull. Earthq. Eng., 2020 1-34. https://doi.org/10.1007/s10518-020-00928-7.

[23] M. Donà, L. Xu, P. Carpanese, V. Follador, F. da Porto, L. Sbrogiò, Seismic fragility and risk of Italian residential masonry heritage, in: Brick Block Mason. - From Hist. to Sustain. Mason., 2020. https://doi.org/10.1201/9781003098508-16.

[24] L. 23/1996: Regulation for School Buildings (in Italian), Off. Gazzette Ital. Repub. N¹5 19th January 1996. Rome, Italy, 1996

[25] Circ 21/01/2019 N.7, Istruzioni per l'applicazione dell" "Aggiornamento delle "Norme tecniche per le costruzioni"» di cui al decreto ministeriale 17 gennaio 2018. (Italian 
Guideline), Suppl. Ordin. Alla "Gazzetta Uff. n. 35 Del 11 Febbraio 2019 - Ser. Gen. (n.d.) 337. https://www.gazzettaufficiale.it/eli/gu/2019/02/11/35/so/5/sg/pdf.

[26] G. Grunthal, EMS98 - European Macroseismic Scale 1998, Conseil de 1'Europe - Cahiers du Centre Européen de Géodynamique et de Séismologie, Luxemburg, 1998.

[27] M. Donà, P. Carpanese, V. Follador, F. Porto, Derivation of mechanical fragility curves for macro-typologies of Italian masonry buildings, in: M. Papadrakakis, M. Fragiadakis (Eds.), Proc. 7th ECCOMAS Themat. Conf. Comput. Methods Struct. Dyn. Earthq. Eng., Crete, Greece, 2019: pp. 24-26.

[28] C. Margottini, D. Molin, L. Serva, Intensity versus ground motion: A new approach using Italian data, Eng. Geol. 33, 1992. https://doi.org/10.1016/0013-7952(92)90034-V.

[29] K. Deb, A. Pratap, S. Agarwal, T. Meyarivan, A fast and elitist multiobjective genetic algorithm: NSGA-II, IEEE Trans. Evol. Comput. 6, 2002. https://doi.org/10.1109/4235.996017.

[30] D.M.LL.PP. 20/11/1987, Norme tecniche per la progettazione, esecuzione e collaudo degli edifici in muratura e per il loro consolidamento (in Italian), Off. Gazzette Ital. Repub. N²85 5th December 1987. (1987).

[31] B. Borzi, M. Onida, M. Faravelli, D. Polli, M. Pagano, D. Quaroni, A. Cantoni, E. Speranza, C. Moroni, IRMA platform for the calculation of damages and risks of Italian residential buildings, Bull. Earthq. Eng., 2020. https://doi.org/10.1007/s10518-02000924-x.

[32] M. Dolce, A. Prota, B. Borzi, F. da Porto, S. Lagomarsino, G. Magenes, C. Moroni, A. Penna, M. Polese, E. Speranza, G.M. Verderame, G. Zuccaro, Seismic risk assessment of residential buildings in Italy, Bull. Earthq. Eng., 2020. https://doi.org/10.1007/s10518-020-01009-5.

[33] F. da Porto, M. Donà, A. Rosti, M. Rota, S. Lagomarsino, S. Cattari, B. Borzi, M. Onida, D. De Gregorio, F. L. Perelli, C. Del Gaudio, P. Ricci, E. Speranza (2021) Comparative analysis of the fragility curves for Italian residential masonry and RC buildings. Bull. Earthq. Eng., 2021. https://doi.org/10.1007/s10518-021-01120-1.

[34] Donà, M., Bizzaro, L., Carturan, F., \& da Porto, F. Effects of business recovery strategies on seismic risk and cost-effectiveness of structural retrofitting for business enterprises. Earthquake Spectra, 35(4), 2019, 1795-1819.

[35] Braga, F., Gigliotti, R., Monti, G. et al. Speedup of post earthquake community recovery: the case of precast industrial buildings after the Emilia 2012 earthquake. Bull Earthquake Eng 12, 2405-2418, 2014. https://doi.org/10.1007/s10518-014-9583-3 